\title{
Interactive comment on "Estimation of surface energy fluxes in the Arctic tundra using the remote sensing thermal-based Two-Source Energy Balance model" by Jordi Cristóbal et al.
}

\section{Anonymous Referee \#1}

Received and published: 20 July 2016

\section{General comments:}

The study analyses the performance of the Two-Source Energy Balance model at three flux tower locations at a Alaskan tundra site. The authors suggest and test model improvements concerning the parameterisations of incoming longwave radiation, soil heat flux, and latent heat flux. Overall they find that the most substantial improvement could be achieved with the adapted implementation of soil heat fluxes. Furthermore the model accuracy compared favourably with other models from literature and in different environments. 
surface energy balance models for Arctic tundra. The manuscript is well-written. However, I have questions about the methodology and I would be happy to see a more substantial discussion of some points. Furthermore, the title, abstract, motivation and conclusion emphasise satellite data, while the methodology only includes satellite LAI but no other satellite input. So either the methods are not complete, or the focus should be more local scale to avoid overselling the study. Nevertheless, I find the manuscript worth publishing in HESS after some revisions. Please do not get distracted by the number of points which I mention - I like the manuscript in general and I would like to stress that the work is really interesting. Good luck for the revisions!

\section{Major points:}

1. The authors stress the point that a remote-sensing based model can be applied at the larger scale (Title, Abstact p. 1, I. 17, 24, 26; Motivation p. 3, I. 1-12; Conclusions p. 15, I. 8-10). However, it seems that (except for the LAI, which is a minor point of the study) this was not done (p. 11, I. 23-24). This is a little bit disappointing after reading pages $1-3$. Therefore I would suggest to force the model with satellite data only and compare the results. If this is beyond the scope of the paper, the authors should adjust the motivation statements.

2. Section 2 is quite long given that the model description is published already. P4 I20 - p5 I12 could be omitted or moved to an appendix as the resistance terms and the sensible heat flux parameterisation are not discussed further in the manuscript. In this case, you could mention after Equation 11 that $H_{s}$ is calculated as a function of the difference between canopy air temperature and soil temperature and of the soil resistance.

3. You show two different approaches for estimating $c_{G}$ (Section 3.2). In both approaches you fit some parameters. However, if I understand it correctly, you use

Printer-friendly version

Discussion paper 
different data for fitting. On what data did you fit the parameters of the first method (p7, I23-24)? Why did you not use the same approach as for the second method, where you split the data set into a calibration and a validation subset? Are the data of all stations combined in a single data set? Do you take an equal amount of data points per station? Are the parameters fitted separately for month? Please describe the fitting approach in more detail in Section 3.2. Would it be possible to use a proxy such as soil moisture to improve the fit? Although you mention that soil type and properties are important, none of your methods takes it into account.

4. In Section 3.3 you describe that you use two different Priestley-Taylor coefficients. Did you consider varying them with soil moisture or LAI? Are they valid for the whole Arctic, or only locally?

5. Figure 2 does not demonstrate a relationship between $T_{R A D}$ and $G$, it merely shows that both variables exhibit a diel cycle (p11, I11-12 \& p15, I1-2). Can you please provide more details on the expected relationship? I find that this is an important point as one of your main conclusions is that the approach using $T_{R A D}$ is better than using $R_{N}$. If I understand your reasoning correctly, you assume that the relationship between $T_{R A D}$ and $G$ holds for different vegetation types, times of the growing season and weather conditions. This point needs to be discussed in more detail. For example, a recent study by Juszak et al. (2016) showed that two different vegetation types with close to identical top soil temperatures differed in $G$ by a factor of 2 . It would be great if you showed evidence for this relationship under different conditions. I would at least expect to see scatterplots of $T_{R A D}$ and $G$ as compared to $R_{N}$ and $G$ and correlation coefficients. Of course you can use shifted time series to account for the time lack.

6. The results and discussion in Section 6 are for all stations combined. However, it would be interesting to read about the different (or similar) accuracies at the

Printer-friendly version

Discussion paper
Interactive

comment 
different vegetation types. This is particularly relevant if you want to conclude on vegetation dynamics and vegetation change (p14, 120-22). Figures 4 and 5 also reveal differences between the stations. For example $L E$ is strongly overestimated at the tussock site. Why?

7. Why do you discuss the accuracy of $R_{N}$ (p12, I8-16; p14, 16-11, |24, |30-31, most figures and tables) and not of the incoming longwave radiation alone? If you use the shortwave radiation budget and outgoing longwave radiation from measurements and just compute the incoming longwave radiation in your model, it would be surprising if you found a substantial difference in $R_{N}$. Did you use any of the remote sensing products (p12, 115-16) to justify your conclusion that 'this methodology scheme can be used to obtain reliable estimates of $R_{N}$ '?

8. All Figure legends, scale bars and axis labels are far too small. Please increase the font size to about the same as the figure caption. Please also avoid to rotate the figures (in figures $6,8,9$ ) and the axis labels.

\section{Specific comments:}

p1, 119 What is unique about tundra conditions?

p1, 124-25, Section 2 How did you test the usefulness of the MODIS LAI? Maybe it would be helpful to compare the results of the three towers concerning the different LAl. Also, did you test if the model is sensitive to LAl variations? Which fluxes are influenced by LAI in the model?

p1, 129 Omitting 'Near-surface or shelter level' would make the starting sentence more catchy. 
p2, 115 Do you really mean 'inconsistent', or rather 'sparse'?

p2, 118 What is an 'increase in peak vegetation'? Do you mean vegetation growth / activity / LAI?

p2, 119 Do fires contribute to the greening? Maybe it would make sense to exchange the first two sentences of this paragraph.

p2, 124-25 As shown in the recent paper by Williamson et al. (2016), the albedo effects of shrubs may not be as clear. Also, wet surfaces and sparsely vegetated water may have an even lower albedo than shrubs (Gamon et al., 2012).

p4, 17 Does this mean that the model uses a spherical leaf angle distribution for all vegetation? How do the results change, if an erectophile distribution is used for the graminoid vegetation (fen, tussock tundra)?

eq. 1, 4-12 It is a bit confusing that $R$ can be radiation or resistance, depending on the subscript. Maybe you could use ' $r$ ' for the resistance values?

p5, 125 The abbreviation TIR is not explained. Additionally, this paragraph suggests that the satellite data is used for the study. If this is not the case, delete the clause 'when daytime TIR satellite imagery is typically acquired'.

Section 3.1 Why do you continue using the Brutsaert (1975) formula? Two comparison studies on empirical parametrisations of incoming longwave radiation found that other formulars described the data better, namely the Dilley and O'Brien (1998) clear sky formula and the Unsworth and Monteith (1975) cloud correction (Flerchinger et al., 2009; Juszak and Pellicciotti, 2013).

Printer-friendly version

p7, 15 \& p.7, $125-29$ Actually, in Eq. 12, not $R_{N}$ is used but $R_{N S}$. Please make more clear which variable you use. And if you adjusted the model in case you use $R_{N}$.

Discussion paper

p7, 18-14 Exchange this paragraph with the first paragraph. 
p7, 115-17 Split the sentence in two parts as the 'while' does not follow easily on the first part of the sentence.

p7, 123-24 Why does this sentence not appear in the results section?

p8, 113 Remove '1.2.1'.

Interactive

comment

p9, 18 Are you sure you have several Dryas species (as indicated by spp)? Also, Dryas is a dwarf shrub species, so it would be more accurate to write '..., other dwarf shrubs, and lichen'.

p9, 111 What do you mean by 'vegetation-based measurements'? Maybe replace the term with 'canopy structure' or 'vegetation properties'.

p9, 121-22 Other comprehensive LAI data from close-by can be used as reference, e.g. Shaver and Chapin (1991); Shippert et al. (1995); Williams et al. (2001); Walker et al. (2003); Williams et al. (2006); Shaver et al. (2007); Sweet et al. (2015). In particular the study of Williams et al. (2006) has many details on different types. I am sure there are even more studies which measured LAI as the Imnavait Watershed and Toolik lake are very well studied.

p9, 124-27 The method to estimate $f_{G}$ is not clear to me. How do you estimate the fraction of absorbed PAR by the green vegetation? Is it equal to $P A R_{\text {incoming }}-$ $P A R_{\text {reflected }}$ in your model? This would also include PAR absorption by bare soil, dead plant material, mosses and other elements. Guzinski et al. (2013) actually suggests to use a different method, based on NDVI and EVI (as you mention on page 14). Do you have another reference that actually recommends the PAR ratio method?

Printer-friendly version

p9, 129 Can you explain your choice of 1 for the clumping factor in more detail? What is a 'variable organic layer'? 
p9, 130 Vegetation height and the clumping factor are not variable. Can you estimate the uncertainty you introduce with this assumption?

p10, 11-2 The sentence about future work should be moved to the discussion or conclusions.

p10, 112-13 Why do you restrict the modelling to daytime conditions? It would be interesting to also test if the model is able to reproduce values at night. I am aware, that the incoming longwave radiation depends on cloud cover. However, you could interpolate the cloud cover during the night. How did you assess the presence of precipitation?

Section 5 Using five different error estimates does not add additional information as compared to using only three. In your results, you rarely mention MAD and the information of MAPD and RMSE is largely the same. It is not very intuitive that in your notation the mean of $e_{i}$ is $\bar{X}$. You could use $e_{i}$ and $\bar{E}$ or $x_{i}$ and $\bar{X}$ (and the corresponding notation for $o_{i}$ and $\bar{Y}$ ) instead.

p11, $121 \&$ Table 4 What is this flux subset? Please describe the choice of the subset in the methods.

p11, 123-24 The first clause of the long sentence is out of place, it is an outlook and would fit better at the end of the conclusions.

p12, 12 To which method do the $R^{2}$ and the RMSE value belong?

p12, 11-7 You found that the new method was not better than the original Brutsaert (1975) formula. However, this does not necessarily imply that the Brutsaert (1975) method is good. I would like to see a discussion of limitations and other potential approaches.

p12, 118 What is the 'evaluation subset'? 
p12, 130-32 The BR and RES methods need to be explained in the methods section. How does this description relate to the Priestley-Taylor approach you explain in the methods? Do the two methods refer to the canopy or the soil $L E$ (eq. 10, 11)?

p13, 126 Is the fraction of vegetation cover not estimated from the PAR budget? Please explain this in the methods! How sensitive is the model to LAI?

p13, 130 An LAl of 1.7 seems to be quite high for the Imnavait Watershed. Did you compare with other data such as (Shaver and Chapin, 1991; Shippert et al., 1995; Williams et al., 2001; Walker et al., 2003; Williams et al., 2006; Shaver et al., 2007; Sweet et al., 2015)? Which vegetation type had this extreme value?

p13, 130 Is $f_{G}$ a sensitive parameter?

p14, 126 As the interannual variability is not mentioned in the results, it should not be mentioned here.

$\mathbf{p 1 5}, \mathbf{1 3}$ 'other models' is unclear. Do you mean ' $G$ computation from $R_{N}$ '?

p15, 13 As some readers start with reading the conclusions, it would be good to repeat that $\alpha_{P T C}$ is used to estimate $E T$.

p15, 16 Was the model sensitive to LAI? I would be surprised, as LAI (in the model) does not influence $E T$, albedo, or any of the other major fluxes. Otherwise this conclusion is not valid.

p15, 18-10 On which result do you base this conclusion?

p15, 111-14 This seems very abstract. Maybe you could rather conclude on how to integrate more satellite data to apply the model to the regional scale. 
Figure 2 The temperature is not in Kelvin. I do not think it makes sense to take the mean of all available data as the station with most data will contribute more and biases can occur, for example if the coldest station on average starts measuring later during the year. I would prefer one plot per station, or a completely different graph (as explained above).

Figure 3 This graph is very important. However, it would be great if you could add uncertainties, or at least standard deviations.

Figures 4-6 In the caption, PTC should be a subscript. This way of plotting does not allow an evaluation of $G$, one of your main focusses. Also, it is impossible to tell the accuracy of $L E$. I suggest to use just one variable per panel and indicate the point density with colour (heat map). As this will result in four times more panels, I suggest to remove Figure 5 as the additional information is small.

Figure 7 The figure caption should be self explanatory. Please define $f_{G}$.

Figure 8 I would prefer to see a sample time series to 5-day averages of multiple stations.

Figure 9 Change the symbols to make the figure easier to read. With the tiny legend and the turned figure it is impossible. I would suggest to have the same symbol for the same variable, once filled (for observed) and once empty (for modelled).

Table 1 Space missing between Longwave and incoming; the captions says 'Average and standard deviation for the input values were computed for each period and for each site.' However, there is just one value per site given. Which period is it for?

Table 3 MAPD not MADP

Table 5-6 One $H$ misses the subscript. 


\section{References}

Brutsaert, W.: On a Derivable Formula for Long-Wave Radiation From Clear Skies, Water Resources Research, 11, 742-744, doi:10.1029/WR011i005p00742, 1975.

Dilley, A. C. and O'Brien, D. M.: Estimating downward clear sky long-wave irradiance at the surface from screen temperature and precipitable water, Quarterly Journal of the Royal Meteorological Society, 124, 1391-1401, doi:10.1002/qj.49712454903, 1998.

Flerchinger, G. N., Xaio, W., Marks, D., Sauer, T. J., and Yu, Q.: Comparison of algorithms for incoming atmospheric long-wave radiation, Water Resources Research, 45, W03 423, doi:10.1029/2008WR007394, 2009.

Gamon, J. A., Kershaw, G. P., Williamson, S., and Hik, D. S.: Microtopographic patterns in an arctic baydjarakh field: do fine-grain patterns enforce landscape stability?, Environmental Research Letters, 7, 015502, doi:10.1088/1748-9326/7/1/015502, 2012.

Guzinski, R., Anderson, M. C., Kustas, W. P., Nieto, H., and Sandholt, I.: Using a thermal-based two source energy balance model with time-differencing to estimate surface energy fluxes with day-night MODIS observations, Hydrology and Earth System Sciences, 17, 2809-2825, doi:10.5194/hess-17-2809-2013, 2013.

Juszak, I. and Pellicciotti, F.: A comparison of parameterizations of incoming longwave radiation over melting glaciers: Model robustness and seasonal variability, Journal of Geophysical Research: Atmospheres, 118, 3066-3084, doi:10.1002/jgrd.50277, 2013.

Juszak, I., Eugster, W., Heijmans, M. M. P. D., and Schaepman-Strub, G.: Contrasting radiation and soil heat fluxes in Arctic shrub and wet sedge tundra, Biogeosciences, 13, 4049-4064, doi:10.5194/bg-13-4049-2016, 2016.

Shaver, G. R. and Chapin, III, F. S.: Production: Biomass Relationships and Element Cycling in Contrasting Arctic Vegetation Types, Ecological Monographs, 61, 1-31, http://www.jstor.org/ stable/1942997, 1991.

Shaver, G. R., Street, L. E., Rastetter, E. B., van Wijk, M. T., and Williams, M.: Functional convergence in regulation of net $\mathrm{CO}_{2}$ flux in heterogeneous tundra landscapes in Alaska and Sweden, Journal of Ecology, 95, 802-817, doi:10.1111/j.1365-2745.2007.01259.x, 2007.

Shippert, M. M., Walker, D. A., Auerbach, N. A., and Lewis, B. E.: Biomass and leaf-area index maps derived from SPOT images for Toolik Lake and Imnavait Creek areas, Alaska, Polar Record, 31, 147-154, doi:10.1017/S0032247400013644, 1995.

Sweet, S. K., Griffin, K. L., Steltzer, H., Gough, L., and Boelman, N. T.: Greater deciduous shrub 
abundance extends tundra peak season and increases modeled net $\mathrm{CO}_{2}$ uptake, Global Change Biology, 21, 2394-2409, doi:10.1111/gcb.12852, 2015.

Unsworth, M. H. and Monteith, J. L.: Long-wave radiation at the ground 1. Angular distribution of incoming radiation, Quarterly Journal of the Royal Meteorological Society, 101, 13-24, doi:10.1002/qj.49710142703, 1975.

Walker, D. A., Jia, G. J., Epstein, H. E., Raynolds, M. K., Chapin, III, F. S., Copass, C., Hinzman, L. D., Knudson, J. A., Maier, H. A., Michaelson, G. J., Nelson, F., Ping, C. L., Romanovsky, V. E., and Shiklomanov, N.: Vegetation-soil-thaw-depth relationships along a low-arctic bioclimate gradient, Alaska: synthesis of information from the ATLAS studies, Permafrost and Periglacial Processes, 14, 103-123, doi:10.1002/ppp.452, 2003.

Williams, M., Rastetter, E. B., Shaver, G. R., Hobbie, J. E., Carpino, E., and Kwiatkowski, B. L.: Primary production of an arctic watershed: An uncertainty analysis, Ecological Applications, 11, 1800-1816, doi:10.1890/1051-0761(2001)011[1800:PPOAAW]2.0.CO;2, 2001.

Williams, M., Street, L. E., van Wijk, M. T., and Shaver, G. R.: Identifying Differences in Carbon Exchange among Arctic Ecosystem Types, Ecosystems, 9, 288-304, doi:10.1007/ s10021-005-0146-y, 2006.

Williamson, S. N., Barrio, I. C., Hik, D. S., and Gamon, J. A.: Phenology and species determine growing-season albedo increase at the altitudinal limit of shrub growth in the sub-Arctic, Global Change Biology, pp. n/a-n/a, doi:10.1111/gcb.13297, 2016.

Interactive comment on Hydrol. Earth Syst. Sci. Discuss., doi:10.5194/hess-2016-257, 2016. 